Supporting Information

\title{
for \\ Electrochemical detection of gallic acid-capped gold nanoparticles using multi-walled carbon nanotube-reduced graphene oxide nanocomposite electrode
}

\author{
Hashwin V.S. Ganesh, Bhargav R. Patel, Hamid Fini, Ari M. Chow, Kagan Kerman* \\ Department of Physical and Environmental Sciences, University of Toronto Scarborough, \\ 1265 Military Trail, Toronto, ON, M1C 1A4, Canada \\ *E-mail: kagan.kerman@utoronto.ca Tel: +1 4162877249
}

\section{TABLE OF CONTENTS}

Gallic acid-capped Au nanoparticle (GA-AuNP) colloidal solutions..........................S1

Plot of cathodic peak potential vs pH \& plot of cathodic peak current vs pH................S2

Differential pulse voltammograms of citrate-capped AuNPs (alone) and gallic acid (alone) and blank PBS at a bare electrode........................................................S3A

Differential pulse voltammograms of GA-AuNPs at bare and nanocomposite-modified

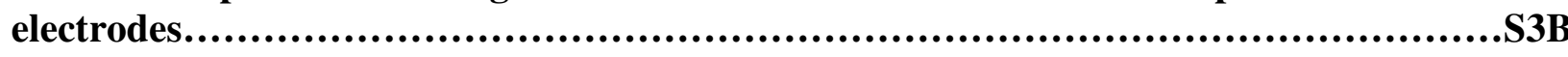

Differential pulse voltammograms of GA-AuNPs and GA (alone) at nanocompositemodified electrodes.

Equivalent circuit elements following fitting of EIS data obtained from bare GCEs and modified electrodes as shown in Fig. 5...............................................Table S1

Bode-Bode plots of the modified electrodes....................................................S5

Differential pulse voltammograms for repeatability studies...................................S6 


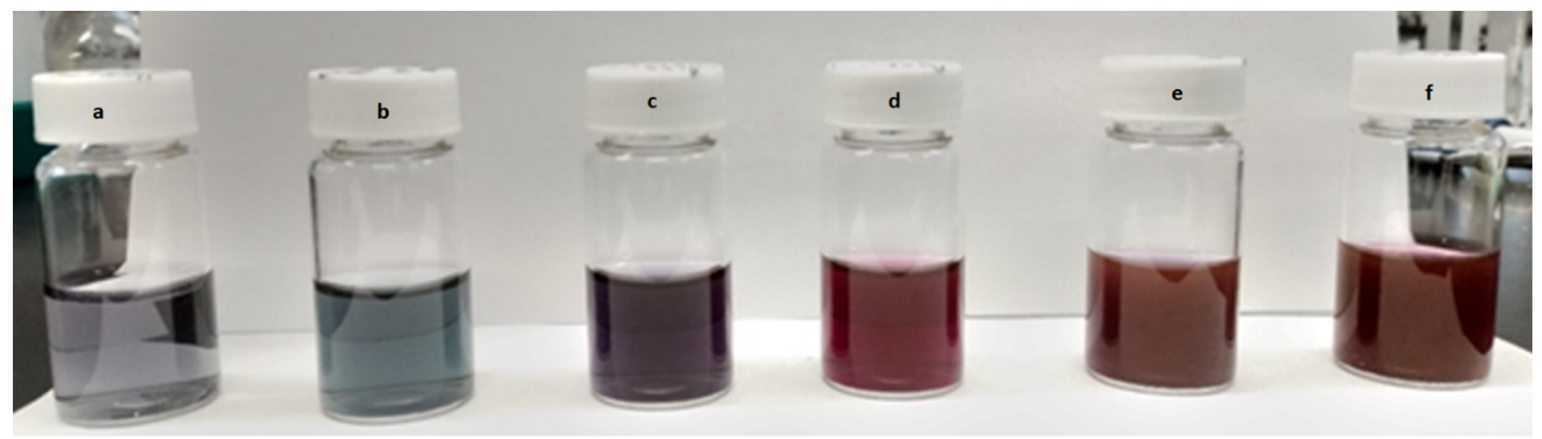

Figure S1 - Photograph showing the colloidal solutions of GA-AuNPs synthesized using varying concentrations of $\mathrm{HAuCl}_{4} .3 \mathrm{H}_{2} \mathrm{O}$ (samples a-f), a) $167 \mu \mathrm{M}$ b) $250 \mu \mathrm{M}$ c) $333 \mu \mathrm{M}$ d) $375 \mu \mathrm{M}$ e) 500 $\mu \mathrm{M}$ f) $537 \mu \mathrm{M}$ during reduction reaction with GA. Colloidal solutions in various colours were obtained depending on the size of the GA-AuNPs produced during the synthesis reaction.

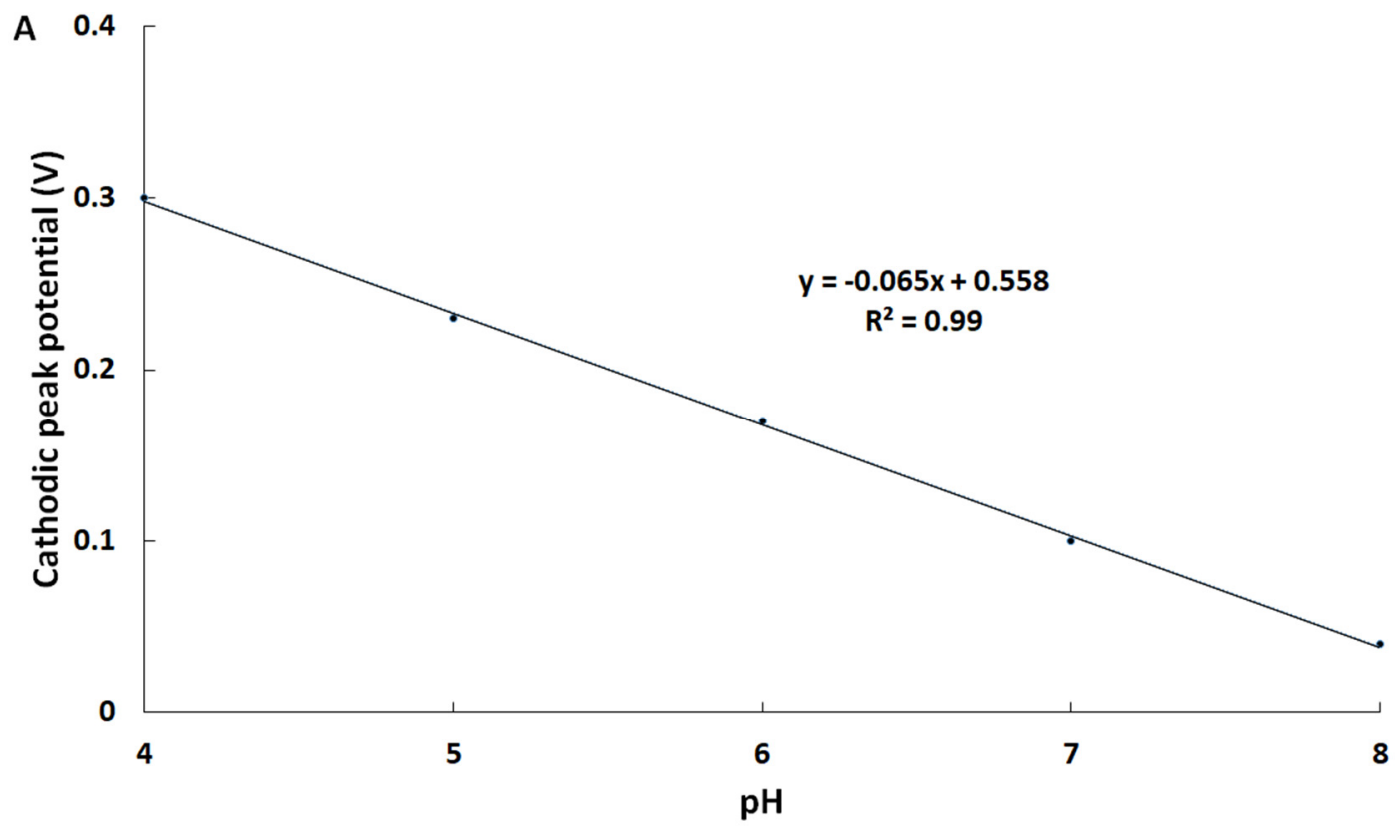

Figure S2A. Plot of cathodic peak potential vs $\mathrm{pH}$ for the detection of GA-AuNPs (85 $\mathrm{pM})$ at MWCNT-rGO-GCE. DPV measurements were performed in $0.1 \mathrm{M}$ PBS at an amplitude of $25 \mathrm{mV}$ and a step potential of $5 \mathrm{mV}$. 


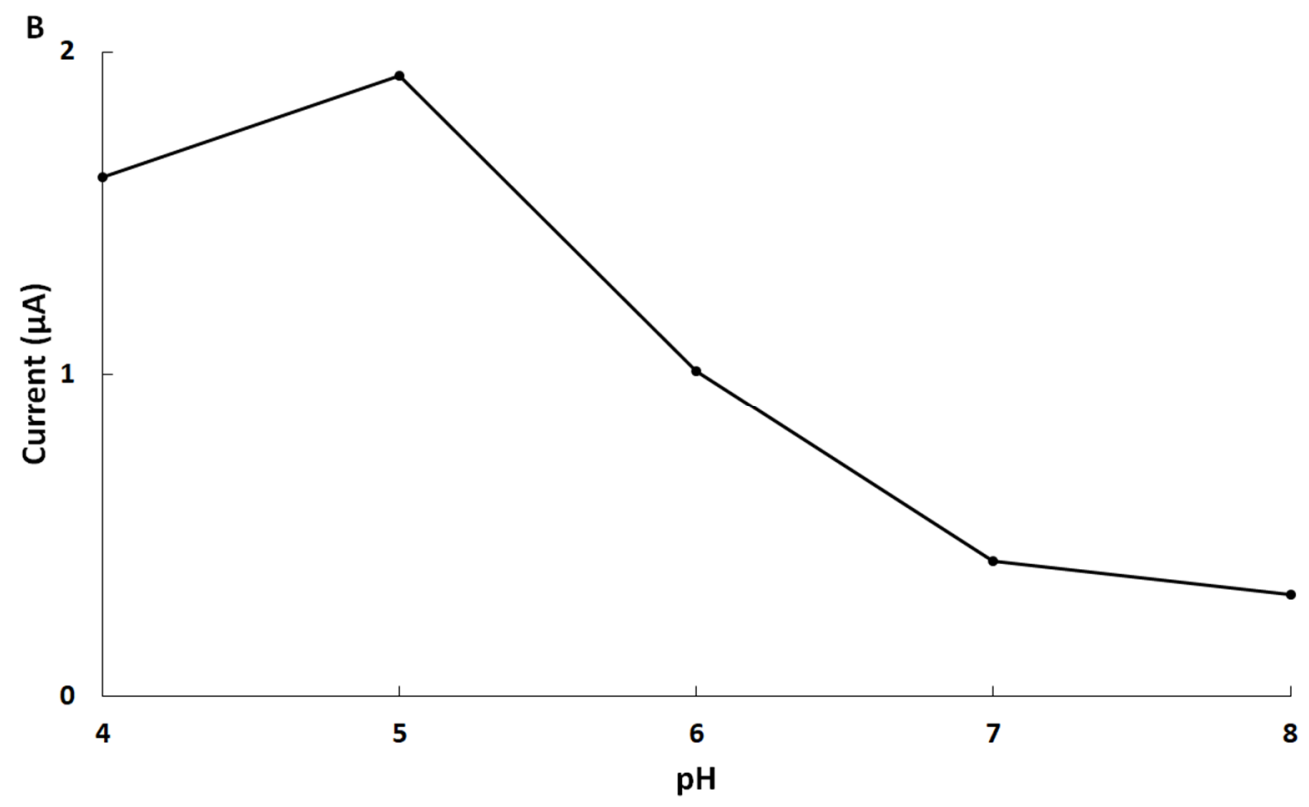

Figure S2B. Plot of cathodic peak current vs $\mathrm{pH}$ for the detection of GA-AuNPs ( $85 \mathrm{pM})$ at MWCNT-rGO-GCE. DPV measurements were performed in $0.1 \mathrm{M} P B S$ at an amplitude of $25 \mathrm{mV}$ and a step potential of $5 \mathrm{mV}$.

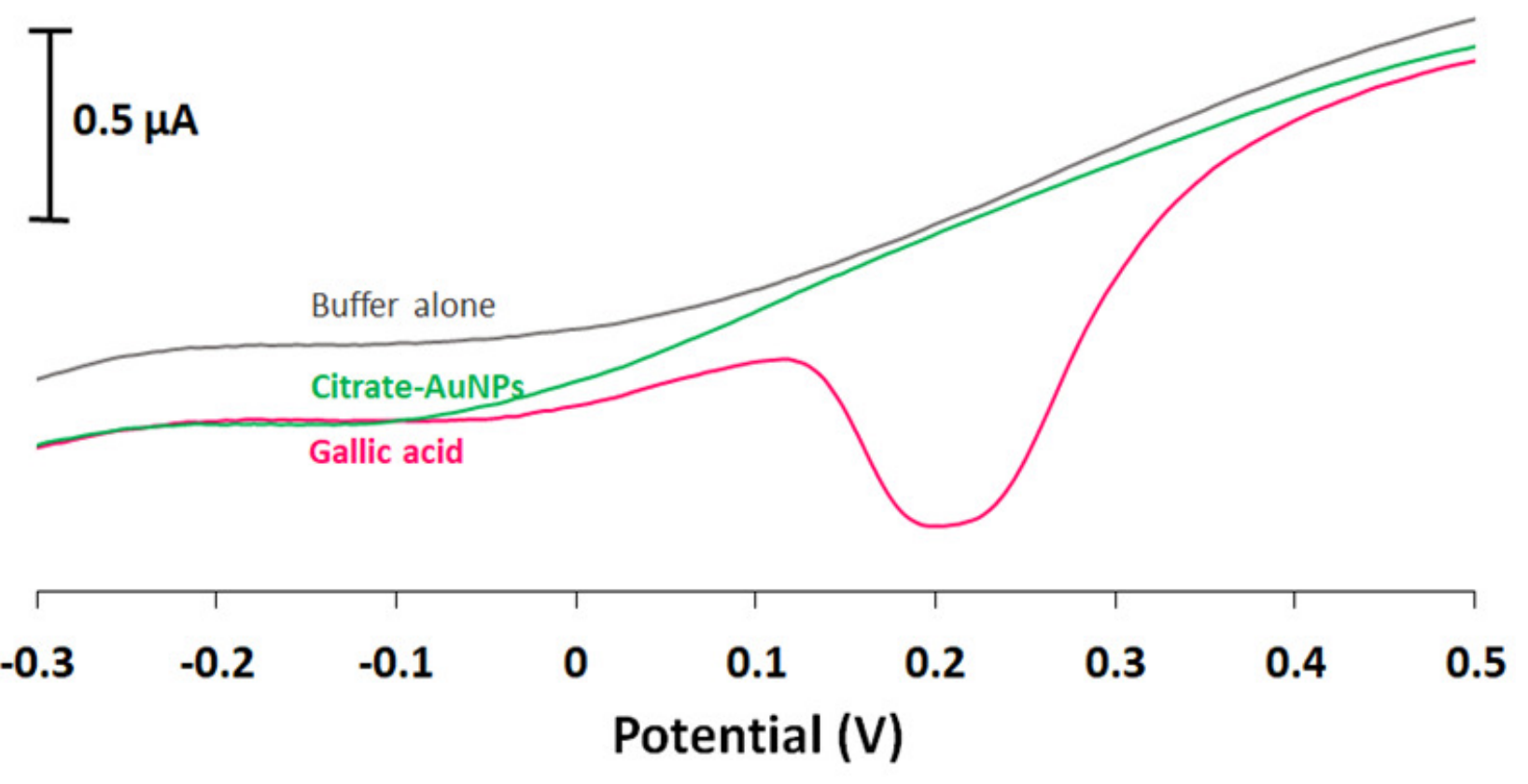

Figure S3A. Differential pulse voltammograms of $85 \mathrm{pM}$ of citrate-AuNPs (green trace) and 300 $\mu \mathrm{M}$ gallic acid (pink trace) at bare GCE. DPV measurements were performed in $0.1 \mathrm{M}$ PBS (pH 5) at an amplitude of $25 \mathrm{mV}$ and a step potential of $5 \mathrm{mV}$ from $0.5 \mathrm{~V}$ to $-0.3 \mathrm{~V}$ (vs. $\mathrm{Ag} / \mathrm{AgCl}$ ). 


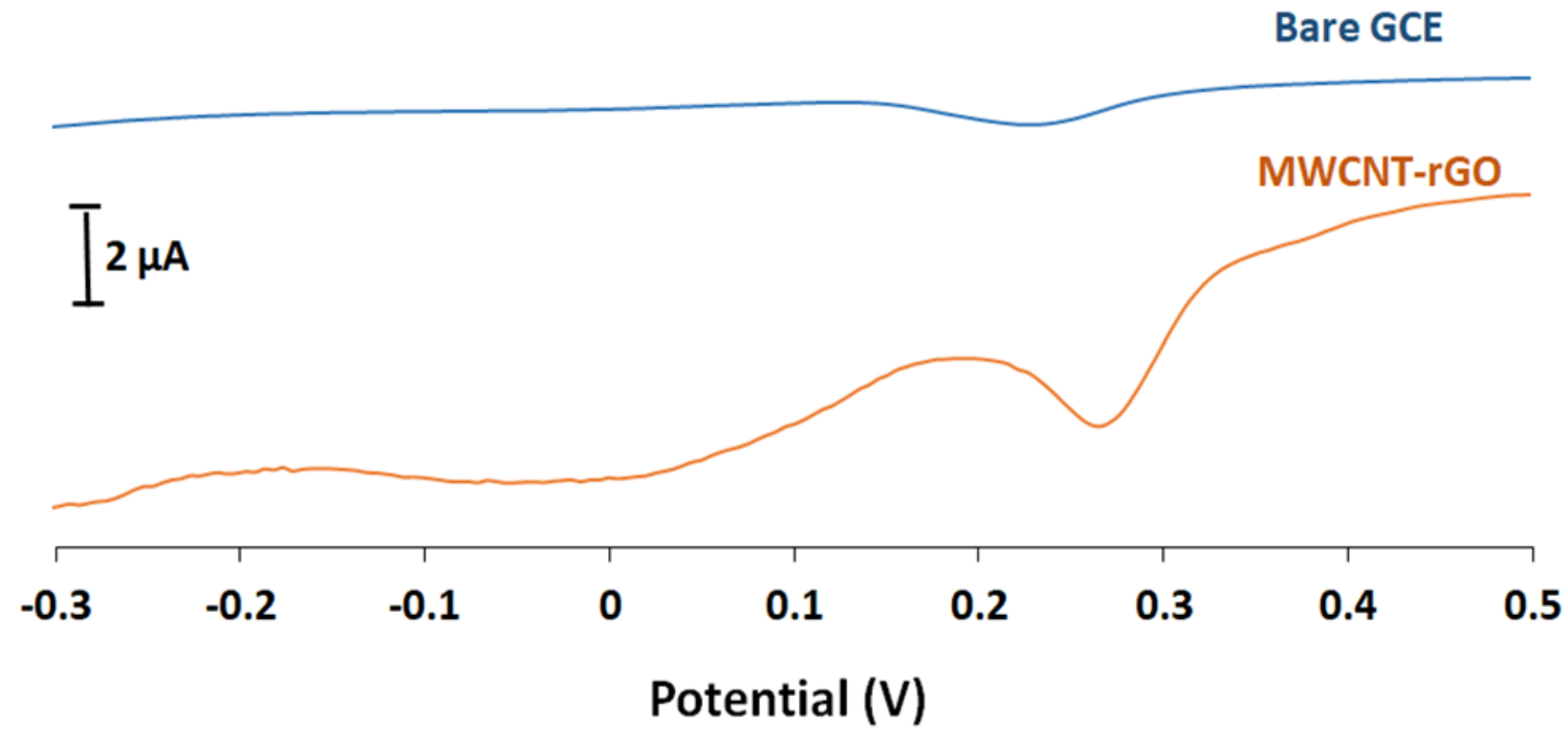

Figure S3B. Differential pulse voltammograms of $85 \mathrm{pM} \mathrm{GA-AuNPs}$ at bare GCE (blue) and MWCNT-rGO modified GCE (orange). DPV measurements were performed in 0.1 M PBS (pH 5) at an amplitude of $25 \mathrm{mV}$ and a step potential of $5 \mathrm{mV}$ from $0.5 \mathrm{~V}$ to $-0.3 \mathrm{~V}$ (vs. $\mathrm{Ag} / \mathrm{AgCl}$ ).

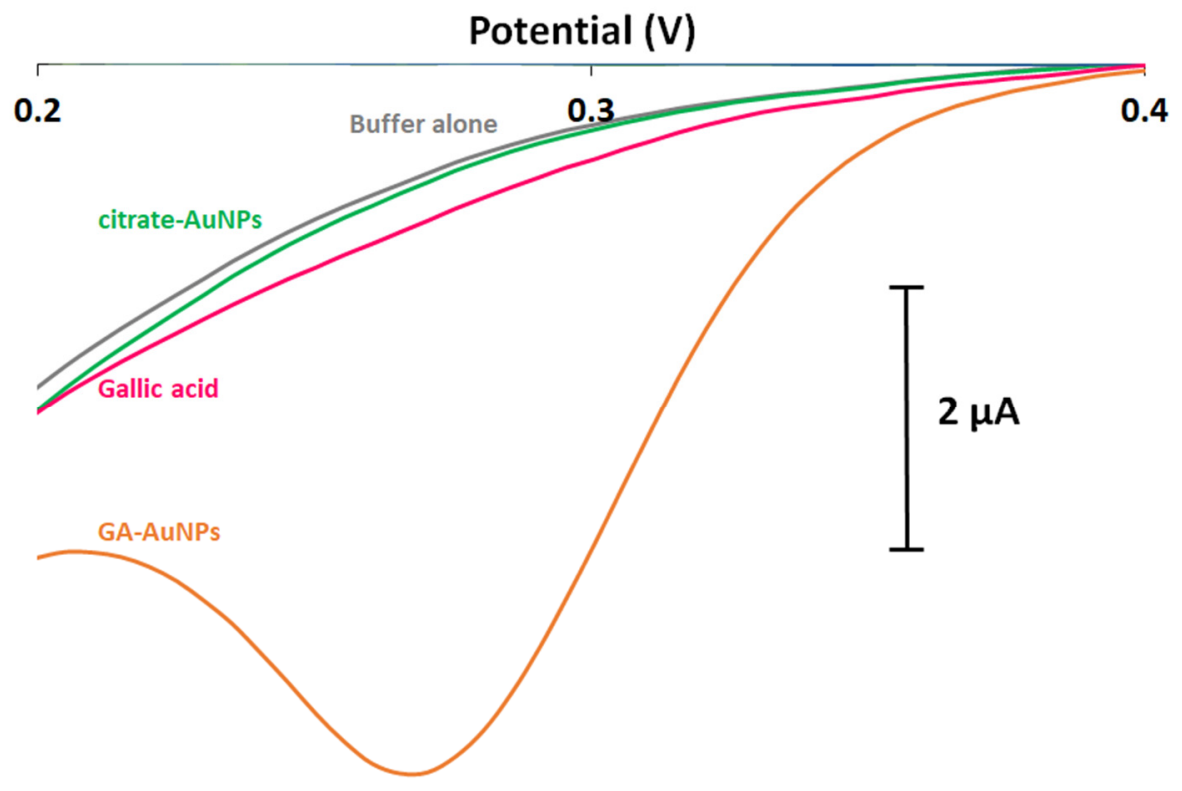

Figure S4. Differential pulse voltammograms of 85 pM GA-AuNPs (orange trace), $85 \mathrm{nM}$ gallic acid (pink trace) and $85 \mathrm{pM}$ citrate-AuNPs (green trace) at MWCNT-rGO modified GCE. DPV Measurements were carried out in $0.1 \mathrm{M} \mathrm{PBS}(\mathrm{pH} 5)$ at an amplitude of $25 \mathrm{mV}$ and a step potential of $5 \mathrm{mV}$ from $0.4 \mathrm{~V}$ to $0.2 \mathrm{~V}$ (vs. $\mathrm{Ag} / \mathrm{AgCl}$ ). 
Table S1. Equivalent circuit elements following fitting of EIS data obtained from bare GCEs and modified electrodes as shown in Fig. 5.

\begin{tabular}{|c|c|c|c|c|c|c|c|c|c|}
\hline & $\begin{array}{c}\mathbf{R} \\
(\boldsymbol{\Omega})\end{array}$ & $\begin{array}{c}\mathbf{R 1} \\
(\boldsymbol{\Omega})\end{array}$ & $\begin{array}{c}\mathbf{R 2} \\
(\boldsymbol{\Omega})\end{array}$ & $\begin{array}{c}\mathbf{Q}_{\text {dl }} \\
\left(\boldsymbol{\mu} \mathbf{M h o} \mathbf{s}^{\mathbf{N}}\right)\end{array}$ & $\mathbf{N}$ & $\begin{array}{c}\mathbf{Q 1} \\
\left(\boldsymbol{\mu} \mathbf{M h o} \mathbf{s}^{\mathbf{N}}\right)\end{array}$ & $\mathbf{N}$ & $\begin{array}{c}\mathbf{Q 2} \\
\left(\boldsymbol{\mu} \mathbf{M h o} \mathbf{s}^{\mathbf{N}}\right)\end{array}$ & $\mathbf{N}$ \\
\hline $\begin{array}{c}\text { Bare } \\
\text { GCE }\end{array}$ & 158 & 573 & n.d. & 10.5 & 0.696 & 42.7 & 0.407 & n.d. & n.d. \\
\hline rGO & 119 & 24600 & 1720 & 8.16 & 0.705 & 635 & 1 & 60.5 & 0.784 \\
\hline MWCNT & 121 & 10800 & 2550 & 5.36 & 0.782 & 28.9 & 0.539 & 9.09 & 1.03 \\
\hline $\begin{array}{c}\text { MWCNT } \\
\text { +rGO }\end{array}$ & 108 & 51.8 & n.d. & 111 & 0.921 & 130 & 0.692 & n.d. & n.d. \\
\hline
\end{tabular}

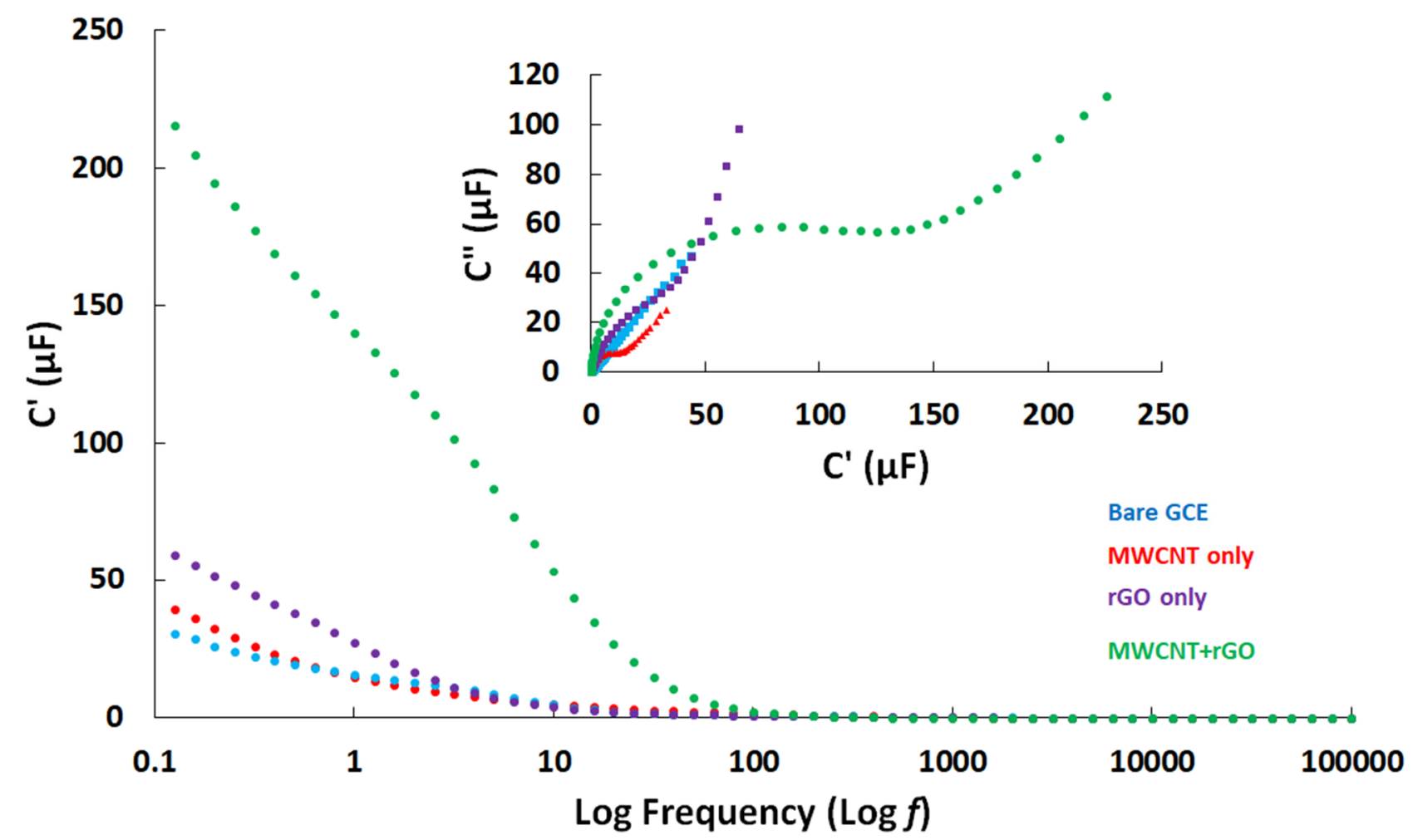

Figure S5. Bode-Bode plots of A) Bare GCE, B) rGO-modified GCE, C) MWCNT-modified GCE and D) MWCNT-rGO-modified GCE. Inset shows the plot of C' vs C' for each of the electrode modifications. Equivalent circuits for each electrode modification are provided in Figure. 5 in the main text. 


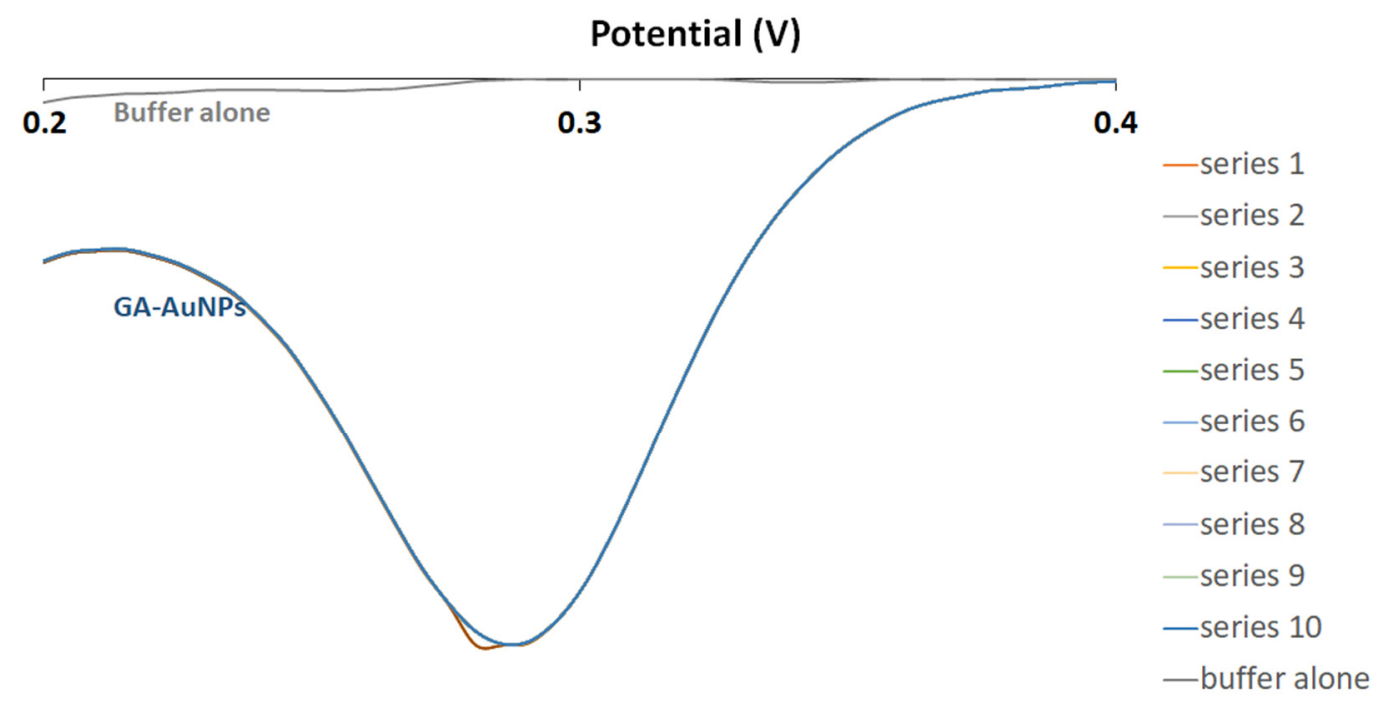

Figure S6. Differential pulse voltammograms of MWCNT-rGO-modified GCEs in 0.1 M PBS $(\mathrm{pH} 5)$ for repetitive measurements $(\mathrm{n}=10)$ of a solution containing $164 \mathrm{pM}$ GA-AuNPs. 